\title{
Peer-Assisted Medical and Health Education: Are we Missing an Opportunity?
}

\section{Ahmed Ezzat*}

University of Aberdeen, Division of Medical and Dental Education, UK

\section{Dear Editor,}

In recent decades, peer-assisted learning has emerged as topical with plentiful interest into its implementation within medical undergraduate curricula. In a way, there is this wonderful rediscovery emerging. At conferences, I almost sense it is as a fashion. Similar to the latest smartphone, peer -assisted learning schemes are a must have, similar to keeping up with technology.

And here I take an issue! As a medical student, I believe something is fundamentally missing in the orchestration and implementation of peer-assisted learning. It has huge potential for medical schools because of practicality, low cost, and sustainability. Essentially, peerassisted learning has happened for decades; defined as people of similar social groupings who are not professional teachers helping each other to learn and learning themselves by teaching [1]. It is not novel; for example: study groups preparing for an exam or group presentations.

But then again, we have been unable to unlock scientific mechanisms underpinning its impact in learning. Planned orchestration is vital to build strong arguments for peer-assisted learning which can be scientifically backed, proven and tested. We require collective and national efforts, through a multi-centred approach, to identify how it differs and why it works. Clear aims and objectives supported by existing learning models are needed, to enrol such schemes further, confidently whilst reassuring the sceptics.
On to its implementation and reference to technology; technologies require artful mastering to boost potential with strong input by its intended users, students; comparably, a new smartphone is best unravelled by younger consumers, or videogames best developed with teenagers rather than their parents.

That is not to say faculty should not be involved, but as all wellintended parents, there is an occasional apprehension in handing over too much responsibility to students. Fundamentally to peer-assisted learning though, students should be entrusted to lead, manage and deliver. Students should be imparted ownership over such initiatives. After all, its appeal stems from this notion of students led by students and for students.

Additionally, faculties having too much input into its operation rather than orchestration can turn peer-assisted learning into yet another chore. Currently, it remains relatively new as an accepted method within undergraduate learning; hence we should develop its culture, as a fun and relaxed way of learning, which in parallel to existing teaching can be as effective; not a replacement rather an alternative or safety-net where resources cannot deliver. Then we can have satisfied students, and consequently better performing medical schools.

\section{References}

Topping KJ (1996) The effectiveness of peer tutoring in further and higher education: a typology and review of the literature. High Educ 32: 321-345.
*Corresponding author: Ahmed Ezzat, University of Aberdeen, Division of Medical and Dental Education, UK, E-mail: ahmed.ezzat.12@aberdeen.ac.uk

Received December 10, 2014; Accepted May 20, 2015; Published May 27, 2015

Citation: Ezzat A (2015) Peer-Assisted Medical and Health Education: Are we Missing an Opportunity? J Health Edu Res Dev 3: 127. doi:10.4172/jherd.1000127

Copyright: @ 2015 Ezzat A. This is an open-access article distributed under the terms of the Creative Commons Attribution License, which permits unrestricted use, distribution, and reproduction in any medium, provided the original author and source are credited. 